\title{
TOWARDS A SEMANTIC BASED HUB PLATFORM OF VAULTED SYSTEMS: HBIM MEETS A GEODB
}

\author{
R. Brumana ${ }^{1}$, P. Condoleo ${ }^{2}$, A. Grimoldi ${ }^{3}$, M. Previtali ${ }^{1}$ \\ ${ }^{1}$ Politecnico di Milano, Department of Department of Architecture, Built Environment and Construction Engineering, DABC LAB \\ GIcarus, Via Ponzio 31, 20133 Milan, Italy - (raffaella.brumana, mattia.previtali)@ polimi.it \\ ${ }^{2}$ Politecnico di Milano, DICA - Department of Civil and Environmental Engineering, Milan, Italy - paola.condoleo@ polimi.it \\ ${ }^{3}$ Politecnico di Milano, DASTU - Department of Architecture and Urban Studies, Milan, Italy - alberto.grimoldi@polimi.it
}

KEY WORDS: HBIM, Heritage Building Information Modelling, vaulted systems, GEODB Hub, Open Access, Stereotomy

\begin{abstract}
:
In the last years many efforts have been invested in the cultural heritage digitization: surveying, modelling, diagnostic analysis and historic data collection. Nowadays, this effort is finalized in many cases towards the Historical Building Information Modelling. The number of informative models testifying the multifaceted richness and unicity of the architectural heritage and its components is progressively increasing. Information and Model are generally acquired under researches and analysis phases addressed to the preservation and restoration process. Unfortunately, once concluded the research such documentation is mostly left abandoned in the drawers or in the local memory of the computers, and in some cases totally missed. Just a few of them are saved in a server or in the cloud for the duration of the restoration, but without any connection with the maintenance process of historic architectures or knowledge transfer purposes and dissemination. This data loss would lead to the breaking of the cycle of past, present and future, with loss of memory and knowledge. The paper start facing the aspect of managing the information and models acquired on the case of vaulted systems. Information is collected within a semantic based hub platform to perform cross co-relation at a PanEuropean level. Such functionality allows to reconstruct the rich history of the construction techniques and skilled workers across Europe, enriched by 3 case studies surveyed in Prague region. To this purpose a Vault DB has been undertaken with a Vocabulary enriched by the granular information gained from the HBIM models, and with the vault sub-typologies highlighted by a detailed surveying.
\end{abstract}

\section{INTRODUCTION}

Heritage Building Information Modelling (HBIM) represents systems capable to correlate 3D Models - describing the volumetric geometry of heritage architectural objects, including the 3D stratigraphic texturing and arrangements (Brumana at al., 2018a) and all the precious elements dense of history (i.e. walls, covering systems, vaults, stairs, windows, doors) - with the different Information collected (materials, construction techniques, dating, historical data, physical properties, data volume for metric computation, archive data, historical documents and so on). The term Informative Model, summarizes the common area of 3D Models connected to Information.

A number of HBIM informative models carried out on different palaces and particularly on their components, as vaulted systems, or covering systems, gave us the opportunity to gain various information from the vaulted system derived from the geometric surveying, the analysis of the construction technologies, as well as their modelling and historical documents. By integrating different surveying technologies and methods (point clouds from laser scans and photogrammetric images, IRT), a punctual analysis of geometry and arrangements has been performed, with a progressively increasing Level of Geometry, Information and Detail. Dimensions, structural elements and components, materials, dates of construction, archive documents and ancient maps have been related within the common working area of the HBIM. Such granular analysis allowed the distinction among the traditional simplified vault typology classification (based on conceptual geometry and simplified concept model), encountering many sub-typologies highlighted analysing the construction technology of the vault components and arrangement techniques with the shapes surveyed; the result is multifaceted richness of solution in the texturing of the masonry elements.

The problem is that HBIM represents a punctual analysis and even if they represent an opportunity to aggregate different information and knowledge, the risk is to lose the achieved level of knowledge, if the results are left, once again, in a drawer when the study, the dissemination effort or the intervention are concluded.

This paper describes the possibility to connect the punctual information models aggregating them as a further step through an hub platform and common vocabulary. Such hub can give to the structured data sources the possibility to be circulated among others HBIM and data sources, generating a network of knowledge. The research here described proposes a methodology to generate an open, updatable repository, reversing the process toward a bottom-up inventory model progressively fed up by the granular analysis carried out within the HBIM generation.

\section{VAULTED SYSTEMS AND VARIETY OF SOLUTONS: TOWARD A CROSS-SECTORIAL KNOWLEDGE AT A PANEUROPEAN LEVEL}

This paper focuses its attention on vaulted systems. Indeed, vaulted systems are characterized by a variety of solutions developed across time and space, and whose knowledge is generally obtained during researches, or analysis and diagnostic

\footnotetext{
* Corresponding author
} 
phases planned for preservation purposes. The richness of solutions adopted during the construction site is mostly unknown to the public, and all the collected information risks to be lost. This leads to an interruption of the knowledge chain, with detriment both of more informed future sustainable interventions and touristic purposes. The potentials offered by the adoption of a Pan European Virtual Hub to manage open data based on semantic, spatial and temporal subsets (Mazzetti et al., 2015), here applied to the vaulted systems, allows to reconstruct a new framework of the different construction techniques adopted around the world, as well as permanencies and mutations respect to the common typologies with the contribution of skilled workers that moved during the centuries across Europe. Vaulted systems represented in the past a common architectural covering that has been diffused across space and time. This result in territorial traditions across Central European, North Europe, Middle East and Pan-Mediterranean regions, to cite just some cases. Thanks to the activities of skilled worker families across Europe the adoption of a multiplicity of solutions overcoming the common typological subdivision, similar construction techniques, arrangements, centrings construction has been progressively documented and can be found across the regions with, at the same time, an unexpected variety of solutions. A notable example are the famous 'Magistri Comacini' from the Como Lake during the Middle Age (Della Torre at al., 1997), and many other traditions as in the case of Jesuits Churches and Palaces in the XVII century, or the decoration skills as in the case of the Carloni family acting in the area of the Como Lake and then in Northern Europe, not to cite the thousands of art craft families working during the centuries known at the local level but mostly unknown to the large public. Different vaulted systems have been obtained thanks to skills and capacities of assembling materials through the construction techniques, such as the ancient skills of stone cutting in the space across the centuries (stereotomy), or brick blocks disposal in the space (Piccoli, 1999), or wooden vaults solutions, and risk to remain without any correlation. The same for the decoration apparatus, stucco and frescoes techniques. Unfortunately, a cross-sectorial awareness of such knowledge is nowadays largely absent, and is sometimes just documented at a fragmented local dimension without any correlation to a global scale, where all the gathered information can be related to each other.

\section{SHAPES AND ARRANGEMENTS VARIATIONS: MULTIDISCIPLINARY INTEGRATION (GEOMATICS AND RESTORERS)}

Different case studies have been collected during the last 15 years. We had the opportunity to study different vault cases, surveying and modelling their intrados and extrados, to investigate the geometric shape, together with thermal image acquisition in order to analyse the masonry arrangements; many data from the private and public archives on the acquisition of the palaces and their transformation occurred during the centuries have been collected (Landi, 2012): an interdisciplinary researches have been carried out among 'Geomatics and Restorers' (Brumana et al., 2018a) with the aim to deeper investigate the vault elements, to improve the knowledge of the construction technologies, to understand the variety of the geometries, thus to better know the structural behaviour, and to properly finalize their conservation. By investigating the $3 \mathrm{D}$ geometry and arrangements, we found out many mixed constructive solutions, obtained from the associations of different typologies, the possibility to go beyond the simplification of the traditional classification of the vault 'typologies', given by many historical treatises of architecture, contributing to highlight many sub-typologies. In particular, cases of morphology tuned toward multiple-generative models have been detected: it is the case of the two sail vaults tuned toward a groined shape, like a morphing among 2 different typologies - a sail dome and a groined vault, respectively coming from a spherical model and from the intersection of 2 cylindrical models - as in the case of the 2 domes of the Church of S.Maria di Scaria (Fedele di Intelvi, Comum, Italy): they have been highlighted thanks to the integration of the Terrestrial Laser Scanning and photogrammetric surveying, with the analysis of the diagonal arrangement viewable from the extrados.

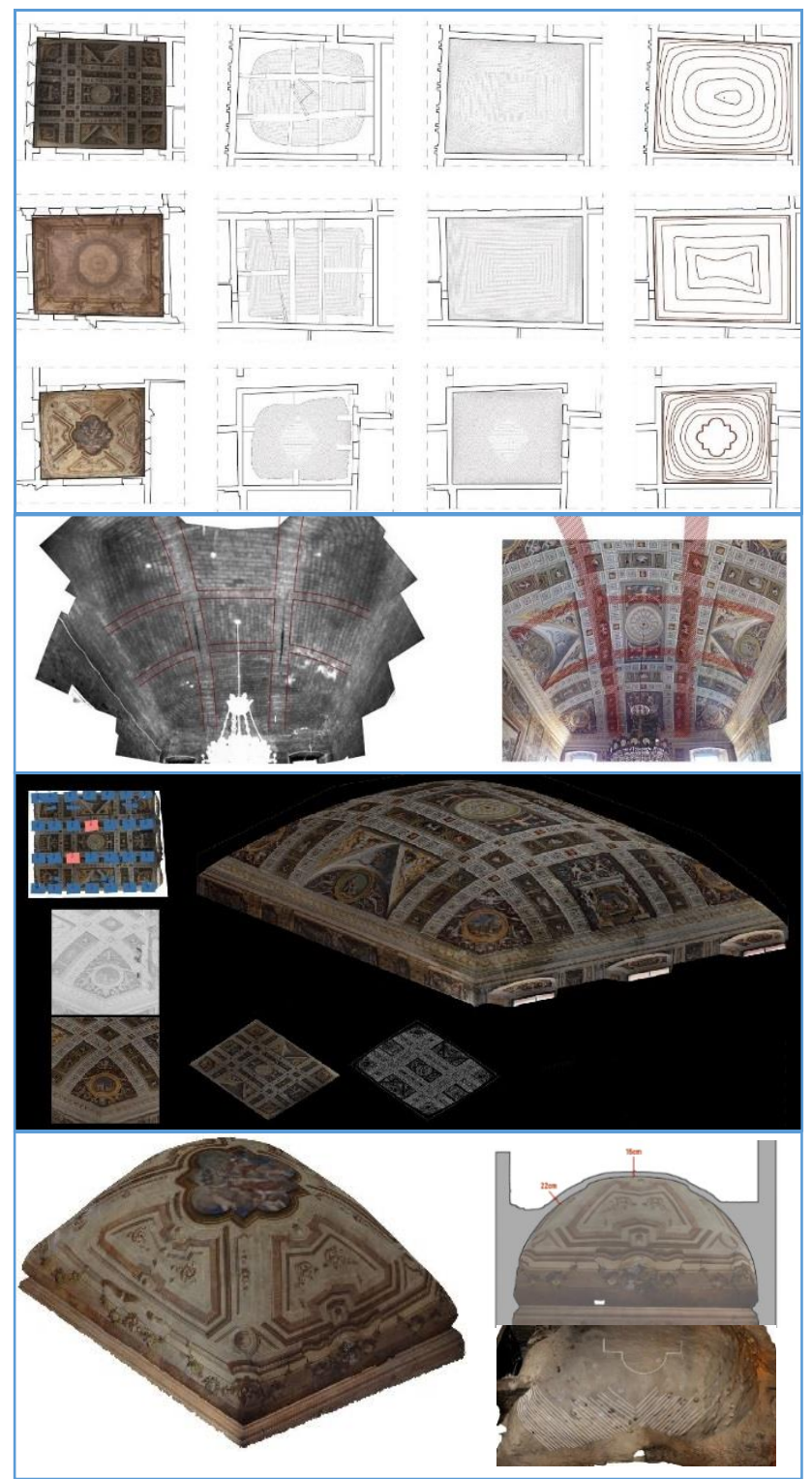

Figure 1. The 3 solutions obtained on the common 'cloister' typology (upper), and some details of the 2 deviations: the Manfredini Hall, Closter - to -Trompe solution (centre), and the Stair Hall, Cloister-to-Dome-to Trompe corners (below); Magio Grasselli Palace.

The result gave back an HBIM 3Dmodel where the spherical conceptual shape is tuned toward a groined shape (Oreni at al., 2013). Moreover, Palazzo Magio in Cremona gave the opportunity to identify different typologies, generating a rich 
abacus of vaults, apparently belonging to a simple 'cloister' typology (Figure 1): it has been detected a pure cloister, the one in the centre of the 3 types, a cloister-to-trompe on the corners (upper) and a dome-to-trompe on the corners (below) to obtain a dome adapted to a rectangular space to give the idea of a cloister vault: three different sub-solutions and construction techniques on the common cloister tyypology (Brumana, 2018a).

The paper focuses on a well-documented case, the Magio Grasselli palace in Cremona in which the cloister vaults of 3 main rooms show different construction systems, although 2 of them they were built almost at the same time (XVIII) and another in the XVII century (Landi, 2011). The thermographic recordings and laser-scanner surveys highlighted the various arrangements used for the cloister vaults.

At the same time, many other authors studied vaulted systems under different points of view across the world, rediscovering specific construction techniques (Holzer, 2013, Piccoli,1999, Napolitano et al., 2017, Capone et al., 2015).

Unfortunately, a lot of drawing and models set-up during such different researches risk to be lost during the years, limiting the possibility to derive transversal connections.

\subsection{HBIMs punctual data and aggregation}

The use of cloister vaults in the construction of noble buildings, as covering elements for square or rectangular rooms, is widespread and well-known: the geometric continuity at the intrados makes generally possible the execution all over the span of frescoes, stucco and decorations. The construction of brick vaults, from the late Middle Age, was sped up by limiting the centring to the wooden planks arches that were instrumental in the profile determination. Nowadays, the availability of procedures and tools to carrying out accurate survey $(2 \div 4 \mathrm{~mm})$ allows to draw reliable assumptions about the construction methods and the execution time. It is mandatory to determine the properties of the binders, the shape and dimensions of the bricks, and to carry out a comparison between the geometry of the intrados surface and the evidences emerging at the extrados. The support of the laser scanner technique allows to accurately identify the surface profile and thickness. All these indications, in turn, are useful, in view of an interpretation of the structural behaviour (Tucci, 2017), to identify weaknesses, and to highlight contributing factors of instability (if any). Generative modelling point cloud processing has been adopted in order to keep the surveying accuracy in the HBIM model (Banfi, 2017). For each of the 3 vaulted sample cases is has been reconstructed an HBIM with the 3D model of each component till to the 3D arrangements. Figure 2 illustrates one of the 3 'cloister' cases, particularly the case of the mixed arched/vaulted solution adopted in the Manfredini Hall faced on the road, with the cloister-to-trompe solution: the thin shells ('in folio' textured) HBIM generation interlaced by the arches is viewable, with the related information on the dimensions, texturing and typology (Brumana et al., 2018a).

\section{SIMILARITES OF CONSTRUCTION TECHNIQUES. THREE CASE STUDIES IN THE PRAGUE REGION}

Since the Medieval time, the Italian architects and builders moved from the North of Italy to the middle Europe to work for the Bohemian aristocracy and to find job opportunities.

In the Modern Age, the Bohemian architecture acquired the stylistic features of French and Italian baroque architecture (Norberg-Schulz, 1968). For this reason, a deeper investigation of the vaulted systems and connections to the Italian ones has been undertaken. Some case studies outside Italy located in the Prague region have been also selected, giving the opportunity to start surveying and modelling of the selected samples aiming to compare the construction methods ${ }^{1}$.

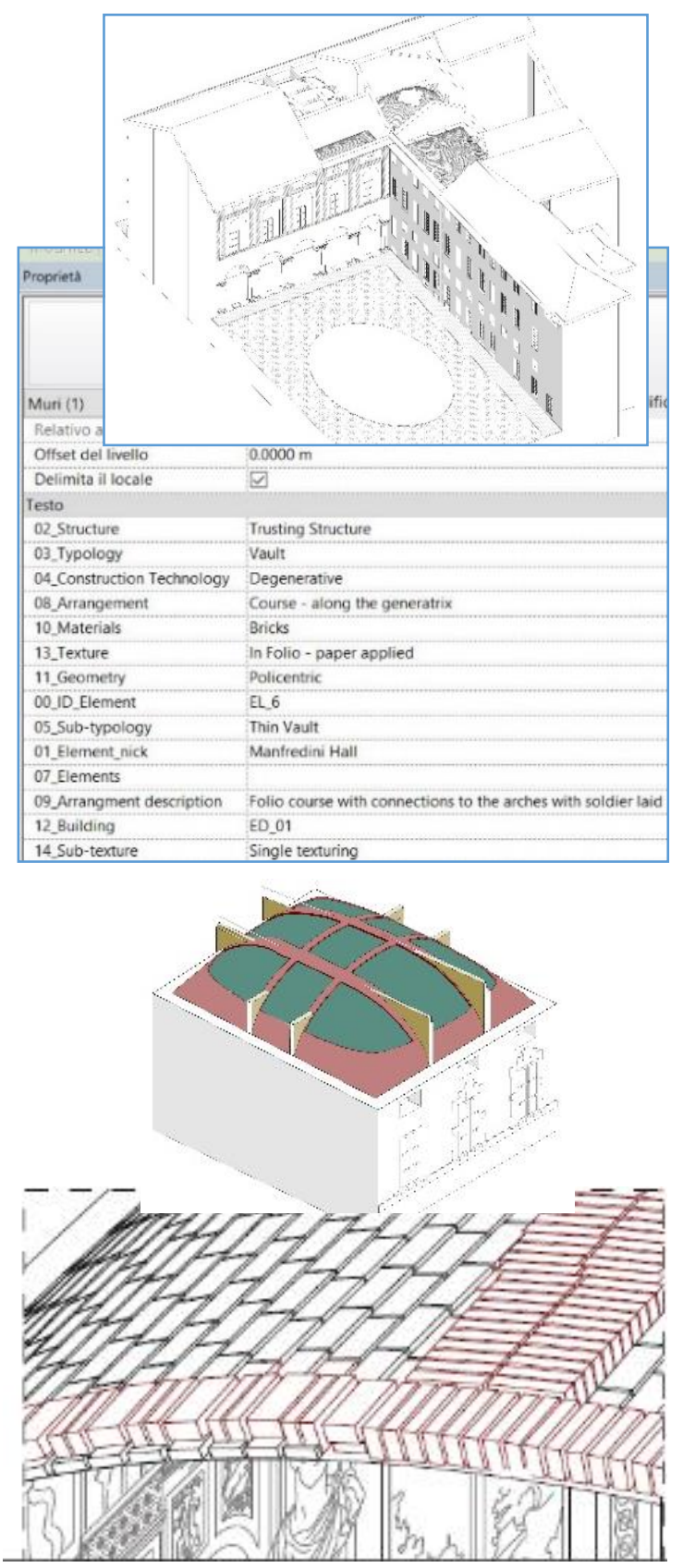

Figure 2. Palazzo Magio Grasselli, the Manfredini Hall. HBIM model and the properties populated with the information detected

\footnotetext{
${ }^{1}$ A six months internship of a PHD visiting researcher Dr. H. Hasníková (Institute of Theoretical and Applied Mechanics, Czech Academy of Sciences) have been hosted at the DABClab GIcarus and collaborated with the POLIMI team to acquire data in Prague and surveying (F.Banfi, PhD, HBIM and modelling, C. Stanga, $\mathrm{PhD}$ candidate, vault interpretation and data collection).
} 
The study involved two vaulted systems in Prague, the Klementinum Baroque Library and the Italian Cultural Institute chapel: the two vaulted systems have been chosen since they represent great examples of the Baroque architecture in Prague. The barrel vault types are turned into two different variations: a barrel vault with lunettes for the Klementinum Baroque Library (with probable extrados arches) and a frame vault for the Italian Cultural Institute chapel. The aim is to start investigating the possible connections between Italy and the Czech Republic: this is the case of the Klementinum main vault, characterized by similar illusionistic frescos, painting and decoration realized by workers coming from the school of Andrea dal Pozzo in Rome. Connections and investigation of the Vault of S.Ignazio are planned for the next year. The Barrel Vault of the Italian Institute of Culture in Prague, is very similar to vaulted mixed arched systems in Cremona. The third case has been chosen in order to consider the mixed arched and vaulted system applied to the umbrella dome covering the St. Bernard's Chapel in Plasy Monastery.

\section{BOTTOM-UP SEMANTIC BASED GEODB}

\subsection{The Vault DB}

All the properties detected by the surveying and HBIM analysis have been managed into a common Data Base (DB). The main steps for the creation of a spatial database model were: (a) characterization of the data and aim of the analysis; (b) set-up of the database model; (c) connection with a Geographic server; (d) online publishing.

Along with the $\mathrm{DB}$, a data dictionary was developed to store information on the attributes defined for each entity: a data entry mask illustrates the architecture of the DB granular information.

The DB architecture developed is continuously tested and adapted in order to entail the richness of the construction systems encountered. Being the methodology (as per its definition) a bottom-up process, the database is populated by different kind of information, providing a new provisional taxonomy detailing the construction technologies and their effects on the geometry (Figure 3 ).

Different information can be updated due to the richness of the DB that has been generated on the base of the HBIM Information input data describing the richness and peculiarity of the vaults: different properties have been inserted in the DB, among which: (i) the building typology the vaults belong to, (ii) the geographic position (latitude, longitude); (iii) the main typology of vault elements, (iv) the sub-typology encountered by the vault HBIM analysis and characterizing each components, (v) the constructive components of the vault system (i.e. the mixed vault and arched system components, or others), (vi) the arrangements with the texturing (i.e. soldier laid or 'in folio' disposition of the brick blocks or stones, double or single layered, others) and the dimensions of the textured elements, (vii) the materials (i.e. stone, brick block, tiles, others), (viii) the different historical phases of construction related to the vault elements; (ix) information on the family workers documented during the researches; $(x)$ free text description, (xi) keywords; together with (xii) technical information on the surveying technique, scale and HBIM Grade of Accuracy of the Model obtained, (xiii) the diagnostic techniques, as in the case of IRT thermal images; (xiv) structural analysis and crack survey DB; (xv) the output generated, the different formats, and the HBIM Model accuracy (LOG-LOA).
The aforementioned examples are just samples to start testing the platform, a Geographic Data Base Hub, (GEODB HUB), linked with: (i) 3D models coming from detailed surveying, (ii) the HBIM from Scan-to-BIM processes, (iii) orthophotos of the intrados and extrados coming from photogrammetry, (iv) texturing detection. An application, GeoPAN APP (Previtali and Latre, 2018) has been developed to access and query the GEODB and it is conceived to support spatial and temporal queries.

\subsection{Toward a semantic based hub platform of vaulted systems}

The availability of Virtual Hubs technologies (Mazzetti et al., 2015) supporting semantic, geographic and temporal queries on Open Data (including Geographic Open Data) has been used to build a web accessible platform where to feed all the data gathered by the surveying and qualitative analysis, together with the historical information acquired on the vault systems (Brumana et al. 2018b).

The paper illustrates the experimentation of testing the methodological workflow starting from the punctual informative models (HBIM) feeding an open access Geospatial Data Base based on a Virtual Hub technology. In particular, the server-side software used is GeoServer a powerful Open Source platform for publishing spatial data and interactive mapping applications on the web. In particular, GeoServer allows the visualization of produced data by using OGC standards like WMS, WMTS, WFS and WCS that are compatible with different solutions allowing datasets to be published on the PanEuropean Virtual Hub.

Currently the link between the GeoDB and other 3D data is represented by an external link. The data that can be linked include: proprietary BIM (e.g., .rfa, .rte REVIT Autodesk (C), OpenBIM, web link (e.g., A360 Autodesk@ Platform), Object Library and 3D mesh models supporting texture (e.g., OBJ, X3D).

For a simple consultation of the data a specific web application was designed (Figure 4) allowing data query and analysis using the Common Query Language (CQL), created by the Open Geospatial consortium (OGC), and an extended version of this language ECQL allowing for ID filters and having a higher similarity with Standard Query Language (SQL).

Let's assume for example to perform a query aimed at extracting only barrel vaults from the GeoDB HUB.

The query can be formulated simply as:

\section{VAULT_TYPOLOGY $=$ 'Barrel'}

In the case we want to filter the results into a specific area, we can specify the query as follows:

VAULT_TYPOLOGY $=$ 'Barrel' AND BBOX (the_geom, TLX, TLY, BRX, BRY)

Where TLX and TLY are the top left coordinates of the bounding box of area we are interested in while BRX and BRY are the bottom right coordinates of the bounding box. Similar queries can be formulated also for temporal constraints. In the future, the system might be implemented as an updatable crowdsourced system.

\section{PANEUROPEAN CROSS RELATIONS}

The possibility of performing semantic queries allows giving back unexpected relationships among different vaults with 
regional widespread, thus contributing to increasing knowledge and rising awareness on the vault constructions across Europe.

Different level of detail, geometry and information, acquired in other Cremona Palaces (Grimoldi and Landi, 2012) and in the Prague area are progressively enriching the DB and its vocabulary in a bottom-up process. The result is a contribution to the construction of an open access updatable inventory model inheriting the tradition of historical repertoires (Figures 4-5).

The result of the DB implemented till now allowed to start reconstructing an updatable vault vocabulary enriched by the specific terminology on the sub-typologies or on the texturing techniques, coming from the analysis of the case studies.

The implementation of the rich terminology gathered by the DB from the case studies within existent on line vocabularies (i.e. the On Line Getty Vocabulary), could be now faced and needs to be further investigated in the future being, to clarify the requirements by the releasing bodies. Innovative repositories can be implemented, reinventing and integrating with new information and knowledge the tradition of the ancient traits describing the different construction techniques of vaulted systems (P. De L'Orme, 1567, Guarini, 1737).

The knowledge enhanced in the last years on these vaulted structures is mostly related to a local historic knowledge, or summarized with few samples in the ancient treatises, or demanded to scientific publications; nowadays the possibility to interconnect all the information coming from the different cases could highlight the rich activity of the family workers across Europe, witnessing a creative fantasy supported by high master level of controlling the construction techniques in the space, thanks to skilled capacities on the stereotomic expertise on managing complex shapes in the space. European worker families whose history has been studied without a systematic approach, and mostly unknown to the large public, can be rediscovered at a PanEuropean dimension: nowadays the low

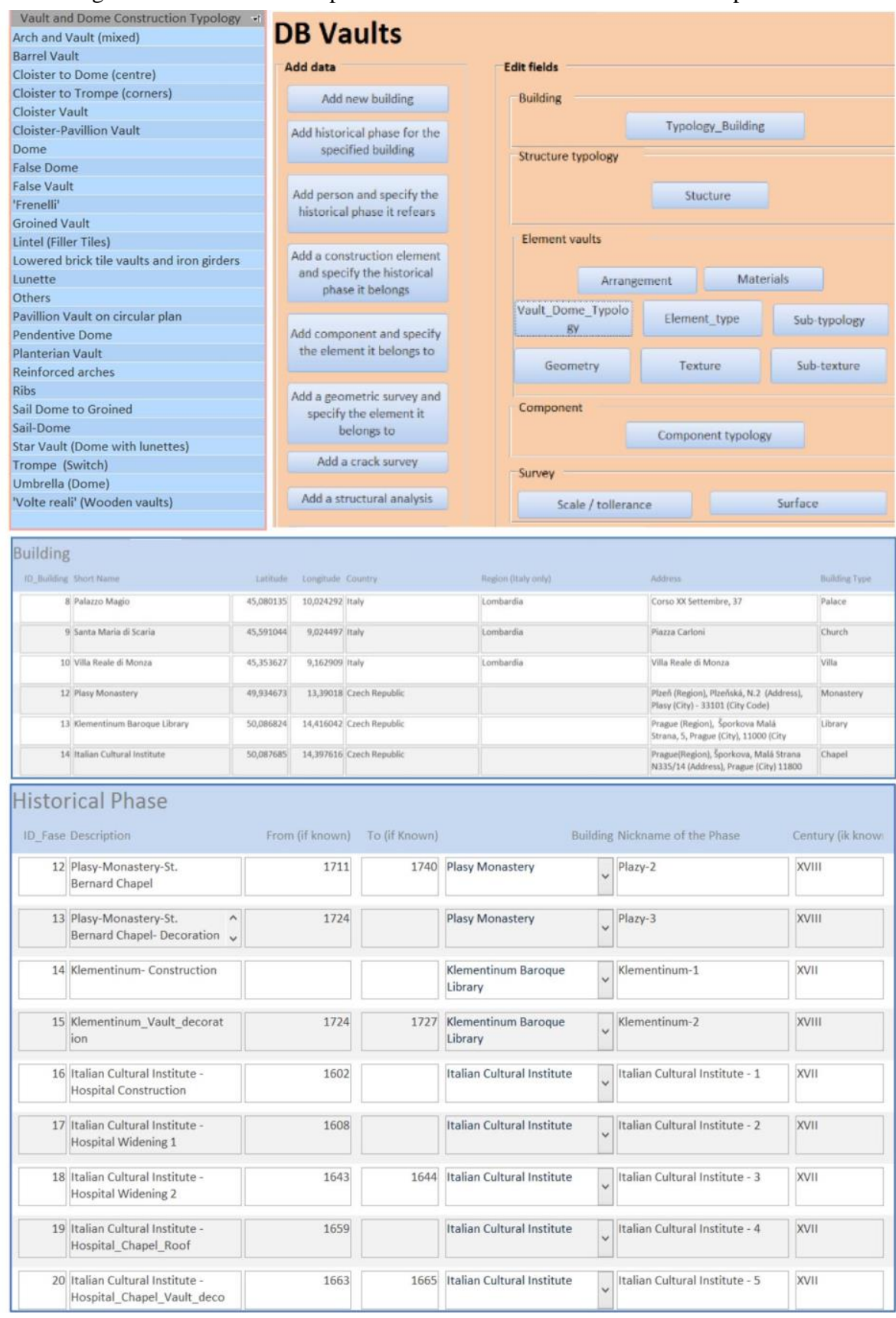

Figure 3. The Vault Data Base with the different description tables related to the Buildings, the Typologies and the Historical Phases of the vaulted systems. The DB has been populated by the HBIM information gathered. 


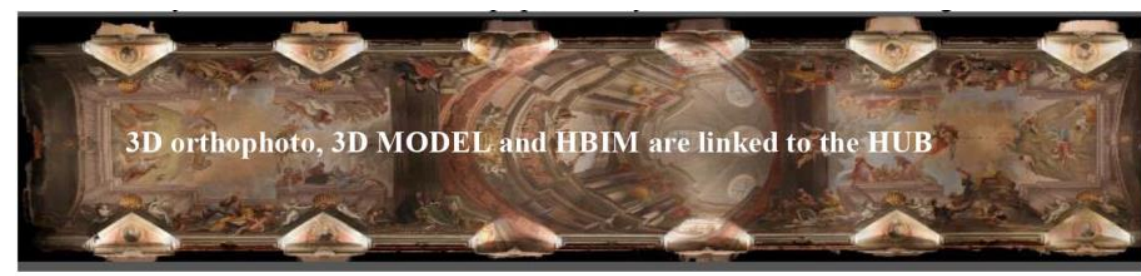

DB VAULT
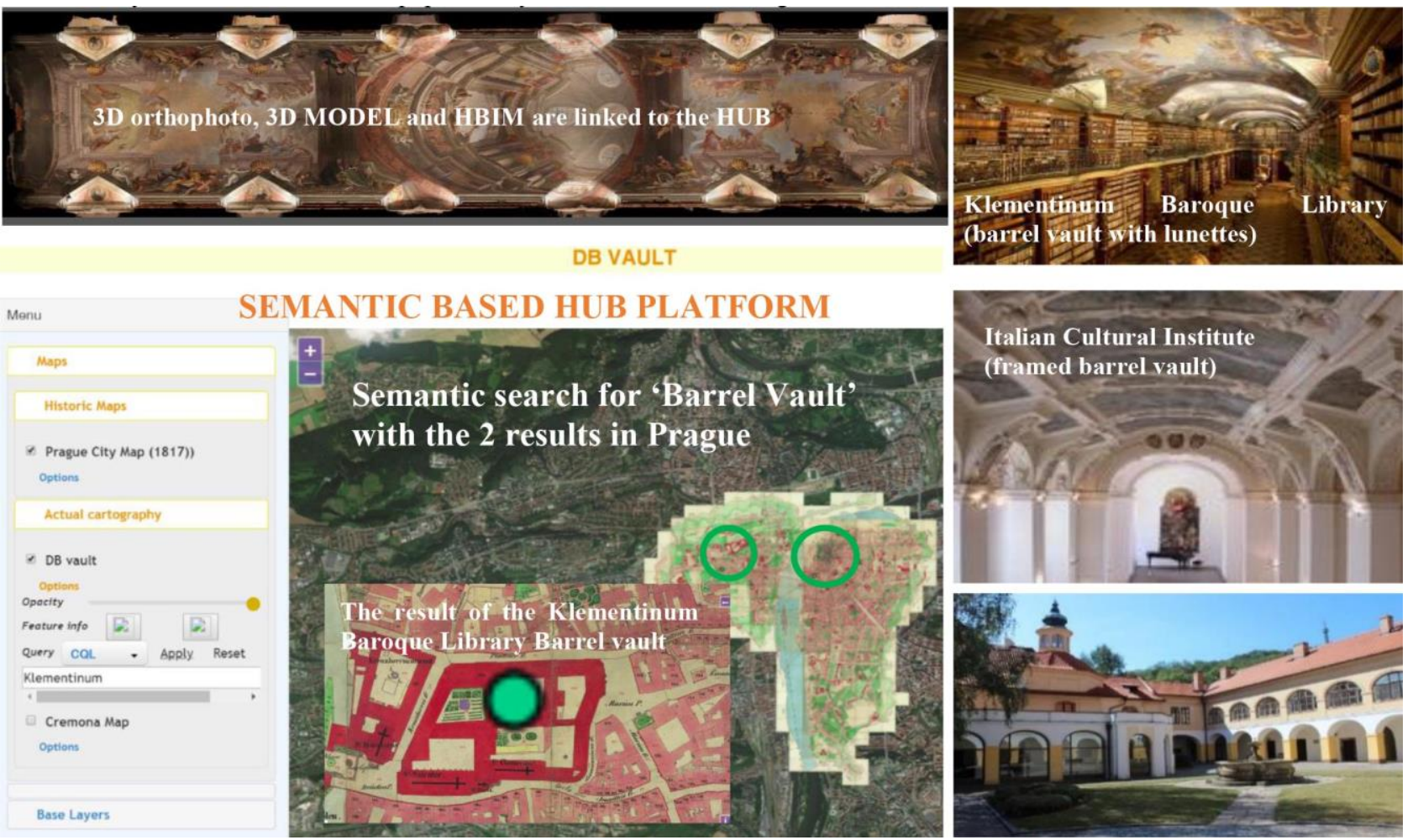

Figure 4. Semantic based hub platform and a query example across EU. On the 3 vaults inserted in the DB coming from the Pargue area, just 2 of them belongs to the Typology 'Barrel vault', the Klementinum Baroque Library, probably with arches, and the Italian Cultural Institute with the framed vault as resulted from the extrados surveying.

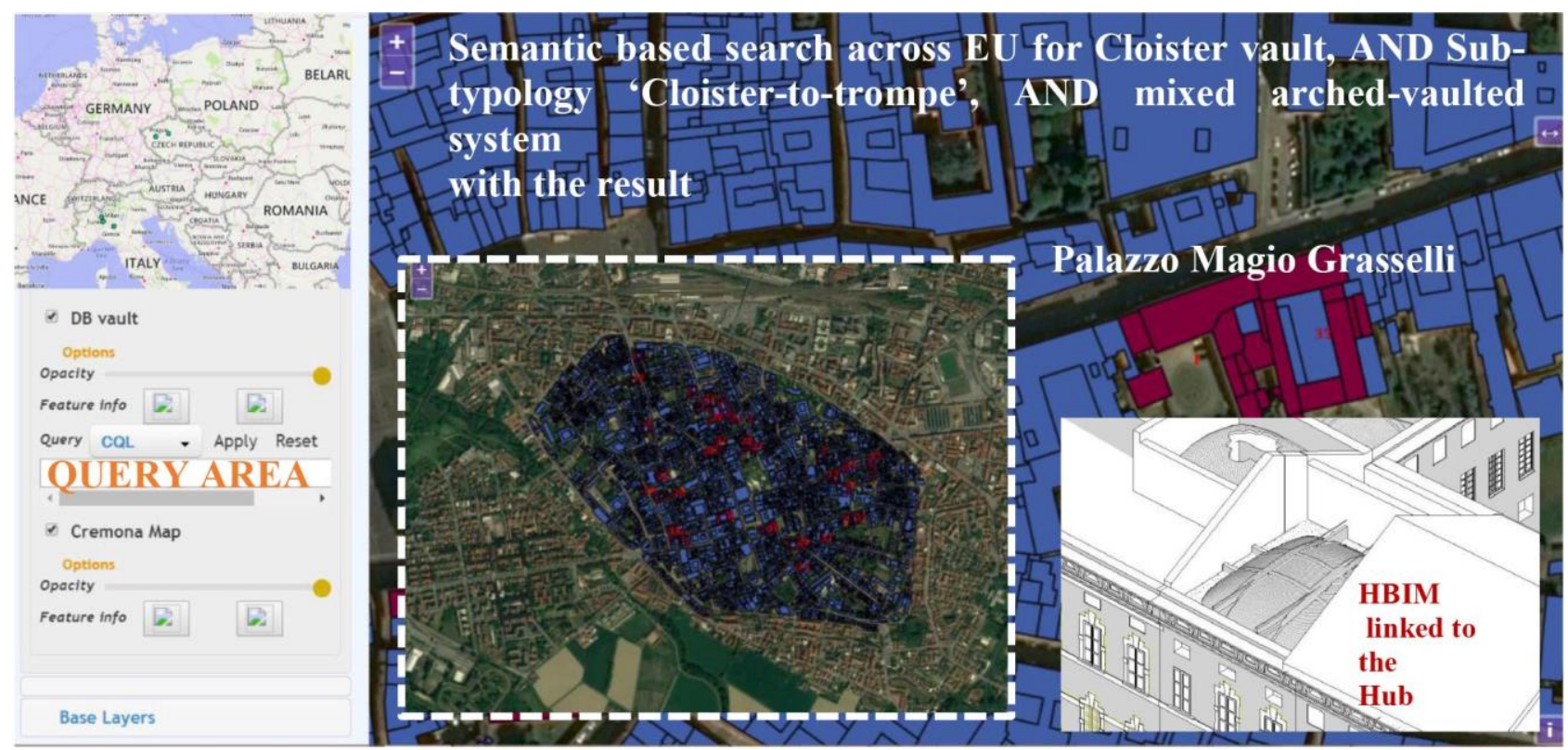

Figure 5. The Vault DB reconstructed form the vaulted system in Cremona. The Palazzo Magio Grasselli and the HBIM linked to the Hub Platform, the Manfredini Hall with the mixed arch and vaulted system (Cloister-to-trompe).

cost and fastness of surveying techniques allows to acquire the single cases in a massive way respect to the past; the GEODB virtual hubs can exploit such potential richness enabling cross correlations to compare their contents across space and time (Brumana et al. 2018b).

It is the case of mixed arched-vaulted systems (Figure 6): the surveying and modelling of the star vault of the Chapel of the Plasy Monastery, together with others on course, highlighted the richness of solutions adopted in such vault construction, their unicity and at the same time their similarities with many other vaults in different European Regions. Such star vaults are in fact characterized by a skeleton made by different shaped reinforced arches and thin web cell lunettes, allowing a multiplicity of outputs, real embroideries on the mixed vault \& arches concept, generating different 'needlework'. The Hub platform query system will allows giving back a PanEu picture with un-expected correlations of traditions, permanencies and mutation across space/time, the skilled workers capabilities across Europe, their movements, enriching the socioeconomic framework of the different periods. Figure 6 illustrates just a 


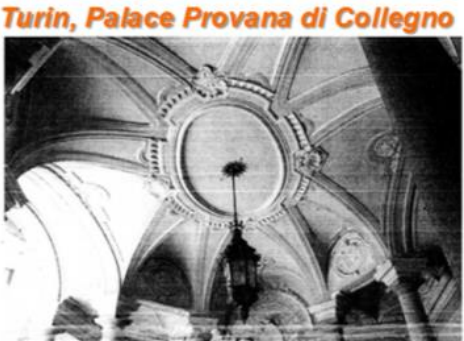

Turin, s. Lorenzo chapel, 1675-1680 (Guarino Guarini)
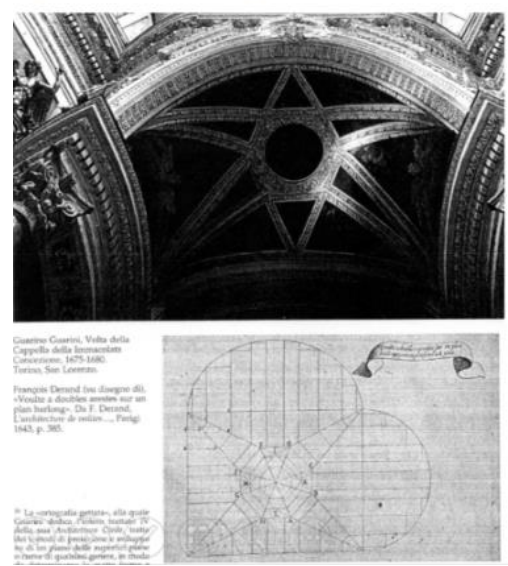
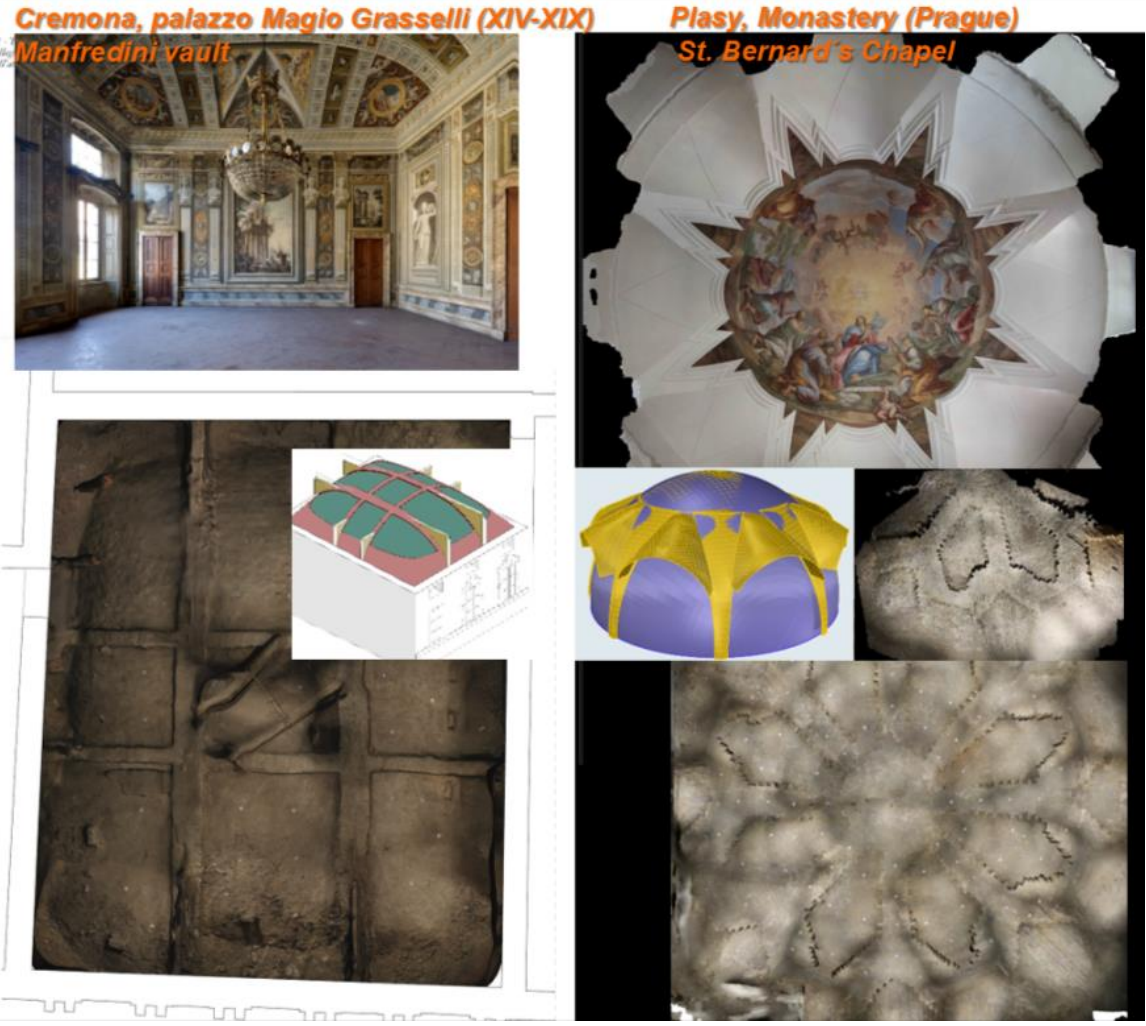

Figure 6. The Hub platform implementation will allow to give back a 'PanEu picture' with un-expected correlations of traditions, skilled workers, permanencies and mutation across space/time, and, thus, the socioeconomic framework of the different periods. Here it is illustrated the case of a sample of the multiplicity of mixed arched-vaulted systems in Turin, Cremona and Plasy (Prague).

sample of the multiplicity of mixed arched-vaulted systems solutions in Turin, Cremona and Plasy (Prague).

A 'live' updatable repository that can be accessed making semantic based different queries. The GEODB hub is not yet crowdsource able, even if it is on course of programme in order to accelerate the data acquisition process by different actors.

\section{REMARKS}

The GEODB hub platform architecture here developed can be tested and adapted on the base of the richness of documented vault systems or other construction elements and techniques. Being the methodology followed to its definition a bottom-up process, the database implements the elements for the main typologies of vault elements, including components, arrangements, properties and a new provisional taxonomy detailing the construction technologies and their related effects on the geometry. It allows to inherit the richness coming from the HBIM high level of detail connecting the different DB information across time and space with possibility of semantic queries giving back unexpected relationship among different vaults with regional widespread, thus contributing to increasing knowledge and rising awareness on the vault construction across Europe.

A further step has been planned for the next years, namely to start implementing a crowdsourced platform self-updatable by different authors: experts, historians, architects, archaeologists, linguists, surveyors. To do that, the definition of IPR roles, code implementation, and requirements for the different linked 3D formats are some of the issues to be faced. Vault vocabulary implementation within existent vocabularies with the rich terminology gathered by the DB from the case studies needs to be investigated.

\section{ACKNOWLEDGEMENTS (OPTIONAL)}

The research leading to the results of this paper is partially funded under the ICT Policy Support Programme (ICT PSP) as part of the Competitiveness and Innovation Framework Programme by the European Community (CIP) GA n ${ }^{\circ} 620400$. The authors would also to thank for researches carried out the within the DABC lab GIcarus the following researchers: on the on the Prague vaults, Ing. Hana Hasníková, visiting researcher at DABC lab Gicarus, Ph.D. (Institute of Theoretical and Applied Mechanics, Czech Academy of Sciences), Fabrizio Banfi and Chiara Stanga, on the vault surveying of Palazzo Magio Grasselli (Cremona, Italy), Dario Attico, Anna Turrina and Fabrizio Banfi.

\section{REFERENCES}

Banfi, F., 2017. BIM orientation: grades of generation and information for different type of analysis and management process. In: The International Archives of the Photogrammetry, Remote Sensing and Spatial Information Sciences, 42(2/W5), pp. 57-64.

Brumana, R., Condoleo, P., Grimoldi, A., Banfi, F., Landi, A.G., Previtali, M., 2018a. HR LOD based HBIM to detect influences on geometry and shape by stereotomic construction techniques of brick vaults. In: Applied Geomatics 10, pp. 529543. DOI 10.1007/s12518-018-0209-3, Special Issue GEORES2017. Geomatics and Restoration: Conservation of Cultural Heritage in the Digital Era ,Springer. 
Brumana R., Condoleo P., Grimoldi A., Landi A.G, Attico d., T., Banfi F. and Previtali M., (2018). HBIM feeding OpenAccess vault inventory through GeoDB HUB, 11196 LNCS, Eds. Fink E., Brumana R.,Wallace M.,Doulamis A.,Patias P.,Ioannides M.,Martins J., Springer Verlag, 10.1007/978-3-030-01762-0_3, pp. 27-38.

Capone, M., Campi, M., Catuogno, R., 2015. Gothic churches in Paris. St. Gervais et St. Protais image matching $3 \mathrm{~d}$ reconstruction to understand the vaults system geometry. In: The International Archives of the Photogrammetry, Remote Sensing and Spatial Information Sciences, 40(5/W4), pp. 423-430.

Della Torre, S., Mannoni, T., Pracchi, V., 1997. Magistri d'Europa. Como: Nodo Libri.

De L'Orme, P., 1567. Traites d'architecture: nouvelles inventions pour bien bastir et a' petits fraiz (1561), Premier tome de l'architecture, presentation par J.M. Perouse de Montclos. - Leonce Laget, Paris 1988.

Grimoldi, A. and Landi, A. G., 2012. The spread of the XVIIth century vaults in Cremona. The case study of Magio Grasselli Palace. In: Jerzy Jasienko (Ed.). Proceedings of 8th International Conference on Structural Analysis of Historical Construction. pp. 1136-1144.

Guarini, G., 1737. Architettura civile, new edition Il Polifilo, Milano, 1968.

Holzer, S.M., 2013. Statische Beurteilung historischer Tragwerke vol. I Mauerwerkskonstruktionen. Enrst \& Sohn, Berlin.

Landi, A., 2011. Riforme edilizie in una dimora aristocratica cremonese: palazzo Magio-Grasselli. In: Landi A. (Ed.), Patrizi, notabili, costruzione della città. Palazzo Magio-Grasselli a Cremona tra civitas e urbs. U. Allemandi, Torino, pp. 33-116.

Mazzetti, P., Latre, M. Á., Ernst, J., Brumana, R., Brauman, S., Nativi, S., 2015. Virtual hubs for facilitating access to open data. In EGU General Assembly Conference (Vol. 17).

Napolitano, R. K., Douglas, I. P., Garlock, M. E., and Glisic, B., 2017.VIRTUAL TOUR ENVIRONMENT OF CUBA'S NATIONAL SCHOOL OF ART, Int. Arch. Photogramm. Remote Sens. Spatial Inf. Sci., XLII-2/W5, 547-551, https://doi.org/10.5194/isprs-archives-XLII-2-W5-547-2017.

Norberg-Schulz, C., 1968. Kilian Ignaz Dientzenhofer e il barocco boemo. Roma: Officina Edizioni

Oreni, D., Brumana, R., Georgopoulos, A., Cuca B., 2013. HBIM for conservation and management of built heritage: towards a library of vaults and wooden beam floors. In: Grussenmeyer, P. (Ed.), ISPRS Annals of Photogrammetry, Remote Sensing and Spatial Information Sciences, vol. II-5/W1. Copernicus Publications, pp. 215-221.

Piccoli, E., 1999. Volte composte nell'architettura piemontese del Settecento: le volte planteriane. In: PALLADIO, VII(23), pp.87-100.

Previtali, M. and Latre, M.Á., 2018. A brokered Virtual Hub approach for the generation of web applications based on historical maps, Appl Geomat (2018) 10: 453. https://doi.org/10.1007/s12518-018-0235-1, 453-472

Tucci, G., Bonora, V., Guardini, N., 2013. Analysis of the factors affecting 3D models resolution-application to the recording of vaults in sangallo's house ISPRS Annals of the
Photogrammetry, Remote Sensing and Spatial Information Sciences, 2 (5/W1), pp. 307-312. DOI: 10.5194/isprsannals-II5-W1-307-2013

GEOPAN APP http://geoserver.atlas.polimi.it/

http://geoserver.atlas.polimi.it/examples/servlets/Geopan/D/Entr y/selector2b.html

Getty Vocabulary, On line Web form, http://vocabcontrib.getty.edu/web-form/login.aspx 